\title{
Isolation of Five Sterols from the Liverwort, Scapania parvitexta Steph. ${ }^{+}$
}

\author{
By Akihiko Matsuo, Mitsuru NakaYama, Shûichi HaYashi \\ and Shigejiro YASUDA* \\ Department of Chemistry, Faculty of Science, Hiroshima University, \\ Higashisenda, Hiroshima 730 \\ *Department of General Education, Hiroshina University, \\ Higashisenda, Hiroshima 730 \\ Received April 22, 1972
}

Liverworts (Hepaticae), which are phylogenetically placed between the vascular plants and the algae, form a unique division in the plant kingdom. They are belived to belong to a very ancient group that evolved along an evolutionary bypath, and their main plant bodies (gametophytes) develops from spores which correspond to the pollens of higher plants.

In spite of phytochemical and biochemical interests in the chemical constituents of the liverworts, investigation has hardly been performed for many years because of a difficulty in collecting a sufficient amount of plants and dissatisfaction in botanical homogeneity.

Recently the authors have investigated the chemical constituents of some liverworts and isolated new sesquiterpene compounds named as chiolscyphone, ${ }^{1 /}$ bazzanene, ${ }^{2 \prime}$ bazzanenol $^{3 \text {, }}$ and $\delta$-cuparenol. ${ }^{\star}$ However, no report has appeared until now on sterol components of the liverworts. The present paper deals with the isolation of five sterols from a leafy liverwort, Scapania parvitexta Steph. (the Scapaniaceae Family).

The liverwort was collected at Yakushima in Kagoshima Prefecture and digested with

$\uparrow$ Chemical Constituents from Hepaticae, Part IX: Part VIII, A. Matsuo, M. Nakayama and S. Hayashi, Chemistry Letters, 1972, 341. methanol after being dried in the shade for a week. A neutral part $(9.3 \mathrm{~g}$; yeild $0.48 \%)$ of the methanol extract thus obtained was chromatographed over a silica gel column $(1.6 \times 45 \mathrm{~cm})$ with a mixed solvent of benzene and ethyl acetate $(4: 1)$ to isolate a fraction (mp $140 \sim 150^{\circ} \mathrm{C}$ ), which gave a positive Liebermann-Burchard color reaction and showed one spot ( $R f 0.38$ ) on TLC using silica gel and the above mixed solvent. The IR and NMR spectra suggested that the fraction was a sterol mixture, and the gas chromatogram, which was determined with a glass column $(3 \mathrm{~mm} \times 3 \mathrm{~m})$ packed with Silicon OV $-1(1.0 \%)$ on Shimalite $(60 \sim 80$ mesh) at $255^{\circ} \mathrm{C}$, exhibited five peaks. In order to identify each of the five components, the sterol fraction was analyzed as the free form and the TMS derivative by combined gas chromatography-mass spectrometry ( $\mathrm{GC}-\mathrm{MS}$ ). In the Table the characteristic ions of the mass spectrum of each sterol are listed. All the compounds gave the same ions of $m / e 273$, 255, 229 and 213 in the free state and predominant ions of $m / e \quad 129$ and $[\mathrm{M}-129]^{+}$in their TMS derivatives. The formers are common in all the mass spectra of these five sterols and are assigned to fragment ions containing the loss of the side chain, and the latters are characteristic to $J^{5}$-sterols. $\mathrm{Be}$ sides, each component has $\mathrm{M}^{+}$and $[\mathrm{M}-15]^{+}$ 
Table. Sterols from $S$, parvitexta and its Characteristic Ions

\begin{tabular}{lccc}
\hline Sterols & $\begin{array}{c}\text { Relative } \\
\text { composition }\end{array}$ & Characteristic ions of each mass spectrum $(\mathrm{m} / \mathrm{e})$ \\
\hline Cholesterol & $1.4 \%$ & $386,371,368,353$, & $273,255,229,213$ \\
Brassicasterol & 13.6 & $398,383,380,365,355,337,273,255,229,213$ \\
Campesterol & 29.3 & $400,385,382,367$, & $273,255,229,213$ \\
Stigmasterol & 43.0 & $412,397,394,379,369,351,273,255,229,213$ \\
j-Sitosterol & 16.7 & $414,399,396,381$, & $273,255,229,213$ \\
\hline
\end{tabular}

ions.

From the above evidence, these components were identified as cholesterol $\left(C_{2 i}, J^{5}\right)$, brassicasterol $\left(\mathrm{C}_{28}, J^{5.22}\right)$, campesterol $\left(\mathrm{C}_{28}, J^{5}\right)$, stigmasterol $\left(\mathrm{C}_{29}, \jmath^{j, 22}\right)$ and $\hat{\beta}$-sitosterol $\left(\mathrm{C}_{29}\right.$, $\left.J^{j}\right)$. This assignment was confirmed by comparison with the authentic mass spectrum as to brassicasterol, ${ }^{5}$ and by comparison of the retention times and mass spectral patterns with those of authentic specimens. ${ }^{6)}$ Relative composition of these sterols thus identified was calculated from the relative peak areas of a gas chromatogram, and is shown in the Table together with the characteristic ions of each mass spectrum.

We expected that the sterol components in the liverworts were similar to these of pollens because both organisms consisted of haploidal plant bodies. However, the sterol components of the liverworts did not give the pattern similar to those of pollens, but the pattern rather resembled that of higher plants.

\section{REFERENCES}

1) S. Hayashi, A. Matsuo and T. Matsuura, Tetrahedron Letters, 1969, 1599; A. Matsuo, Tetrahedron, 28, 1203 (1972).

2) S. Hayashi, A. Matsuo and T. Matsuura, Experientia, 25, 1139 (1969); A. Matsuo, Tetrahedron, 27, 2757 (1971).

3) S. Hayashi and A. Matsuo, Experientia, 26, 347 (1970).

4) A. Matsuo, M. Nakayama and S. Hayashi, Chemistry Letters, 1972, 341.

5) The mass spectrum was kindly supplied by Professor Nobuo Ikegawa, Tokyo Institute of Technology.

6) B. A. Knights, J. Gas Chromatog., 5, 273 (1967). 